\title{
CONSUMPTION PATTERNS AMONG ONE-PERSON HOUSEHOLDS OF NEVER MARRIED IN POLAND
}

\author{
Marlena Piekut, Eng $\mathrm{PhD}^{1}$ \\ College of Economics and Social Sciences, Warsaw University of Technology
}

\begin{abstract}
The scientific objective of the study was to identify consumption patterns in one-person households of never-married women and men, living independently. Ward's grouping method make possible to establish the number of households' clusters. The final stage of household grouping procedure, regarding consumption expenditures was accomplished with $\mathrm{k}$-means clustering method. It can be concluded that distinguishing the consumption patterns for one-person households of never married is possible on the basis of diversification both level and structure of incomes in these households as well as socio-demographic differences between them. Depending on economic and socio-demographic variables, disparate consumption patterns for these types of households can be observed. In addition, it's worth stressing that household having different level of income (although coming from similar source) but similar demographic structure show greater similarity than households having similar financial situation.
\end{abstract}

Keywords: single-person households, consumption, goods, services JEL codes: D12, E21

\section{INTRODUCTION}

Consumption patterns of households are influenced by several factors, among them household size and marital status of household head. The diversity in consumer behaviour of different household types is determined by satisfying consumer needs and characteristics of household members, whereas the hierarchy of consumer needs stays the same.

The literature review indicates that one-person households are under several researchers' attention, as singleness as a life-style is increasingly recognized as the new way of life for numerous women and men. These households not only differ from traditional families, but also are distinct from one another. The problem of consumption patterns is considered mainly with respect to these households as a whole, or to elderly one-person households. However, there is apparent lack of studies on consumption patterns of one-person households of never-married women and men. The subject is considered to be important, as this kind of households is continuing to expand.

The curiosity to learn more about one-person households of never-married became the incentive for conceptualization of research purpose. The scientific objective of the study is to identify consumption patterns in one-person households of never-married women and men, living independently.

The growing number and social significance of one-person households make this research subject

${ }^{1}$ Corresponding author: Lukasiewicza 17, 09-400 Płock, Poland, Marlena.Piekut@pw.edu.pl 
applicable. This study contributes to understanding differences between consumption in various types of one-person households, with particular emphasis on households of never-married.

\section{THEORETICAL BACKGROUND}

The one-person household is the fastest growing type of household in many countries of the world, because of changes in the past few decades in demographic behaviours, institutional arrangements, and labour migration (Yeung and Cheung, 2015). In the past, when living alone could have been a short-term condition, for many it is now a long-term situation. The result of a number of demographic and economic studies over the past half century showed: greater affluence, later ages of marriage, longer lives, smaller family sizes, greater labour force participation, higher divorce and financial independence of women, as well as stronger government safety nets across a broad spectrum of social programs (Masnick, 2015).

According to Euromonitor International forecasts over 2016-2030, one-person households will see faster growth than any other household type globally, with around 120 million new one-person households to be added over the period. The group of elderly widowed and divorced is also growing, especially, this group is large in developed countries. There is also a growing group of young people, never married forming single-person households. In Poland, according to the National Census, the one-person households of young people never married in general of one-person households in 2002 constituted $30.4 \%$ and $35.3 \%$ in 2011. Younger singles exchanging family life for education and careers.

The increase in the numbers of one-person households may have several implications for the economy and many businesses. The growing number of oneperson households will have an impact on numerous industries, ranging from health care to housing. Oneperson households spend more on housing than other households. These households may prefer to rent, not to buy houses. And even if they buy a house, they prefer multi-family houses rather than single-family ones. This may affect the structure of the housing market. A rise in one-person households may aid labour market mobility. With less attachment to property and on marital burdens, these people can be more open to moving cities for jobs. This may make the labour market more mobile than it is today. However, one-person households will have to deal with lower availability of informal personal care from the partners. Such non-market production (as economists would define it) may require replacement of purchased personal care services, in particular health and nursing care, which could significantly affect the health care industry (Bachman and Barua, 2015).

Services take play an important place in the singles expenses. According to studies among Polish singles, in the case of increased income, they spend additional resources on educational, healthcare, tourist and banking services. If they strive to improve housing conditions, purchase of home appliances/au$\mathrm{dio} /$ video devices, or purchase of a car, there is a place activities for accompanying services (Dąbrowska and Janoś-Kresło, 2011).

More one-person households force changes on food processors. Consumers creating one-person households express a greater demand for products of lower grammage, also for products for quick preparation. Studies on food purchasing habits confirm that single-living households are more likely to opt for convenient and other 'easy-to-serve and portion controlled' meal alternatives compared to couples and families with children (Candel, 2001; Harris and Shiptsova, 2007).

As the number of one-person household increases the proportion of expenditures on services is expected to increase while that on necessities such as beverage, food, and energy to decrease. Accordingly policy responses are required to prepare for the expansion of service industries such as housekeeping, health, hospital services. In particular, companies must adopt a strategy targeted at one-person households with high income and purchasing power, such as unmarried professional people.

Jo (2016) showed on the basis of research conducted in single person households in Korea that the income elasticities of all products are greater than 1 except: food and beverages, housing, gas and electricity, water, communication. Income elasticities are significantly different among consuming products. 
In addition, the income elasticities are also different depending on the various age and income groups of one-person households. Therefore governments and companies must take this into account when devising their policies or strategies regarding one-person households.

Statistics showed a high level of heterogeneity among groups who live alone, some of them by choice, others out of need (Yeung and Cheung, 2015). It also indicates the hetrogenity of consumption behaviours in single-person households (Palmer, 2006). The variety of consumption patterns results, from the marital status of the person running the household (Piekut, 2017). Earlier mentioned the aforementioned increase in the share of one-person households of never married is an incentive to identify consumption patterns in these households.

\section{CONCEPTION OF ANALYSIS, RESULTS AND DISCUSSION}

The study was focused on one-person households of never married in Poland. The research material was represented by the statistical data from individual, unpublished CSO (GUS) data for household budget investigations in 2015. The CSO data base for 2015 covered over 37,000 households. There were oneperson households of never married in 2015.

The subject of study is to analyse consumption expenditures so as to create consumption patterns. In the first stage of the study, operational taxonomic units (OTU) were defined. The OTUs were formed on the basis of three socio-demographic variables, i.e. socio-economic, education and age. Then, the grouping procedure was applied for OTUs. Although all the variables (12 categories in expenditures on consumption goods and services) were expressed in PLN, standardization was carried out, since this operation helped avoiding dominating classification by the highest average expenditures. Ward's grouping method make possible to establish the number of households' clusters. The dendrogram was cutoff on the level of 140, which made six groups. The applied criterion was the first significant leap in agglomeration distance. The selected number of groups means the group preceding the first significant leap in agglomeration distance. The final stage of household grouping procedure, regarding consumption expenditures was accomplished with $k$-means clustering method.

The grouping of one-person never-married households made possible to distinguish five groups of these households for data 2015. One of these groups was distinctively greater than the others, which indicates one dominant consumption pattern. Consumption patterns represented by individual groups of households were the result of socio-demographic features of their members.

The specific features of household types and consumption patterns for 2015 are presented below. The largest cluster (the 1st one) covered the youngest people, i.e. below 40 years old, with higher or middle education level. Most commonly, the main source of income for them was white-collar job or self-employment. These households were localized in the largest cities. Slightly more frequently they were female households (58\%). As for expenditures level, in the 1st group, in comparison to others, the largest sum was allocated for dwelling maintenance, education, catering services and accommodation. Relatively high expenditure level for necessary clothing and footwear, transportation, culture and leisure and connected with telecommunication was discerned. In the structure of disposable income, the largest of all other clusters, were expenses of clothing and footwear $(5.2 \%)$, catering services and accommodation $(9.8 \%)$, whereas the shares of expenses of food and non-alcoholic beverages $(12.8 \%)$, alcoholic beverages and tobacco products $(2.5 \%)$ were the lowest of all groups. The share of expenditures on consumption goods and services in disposable income was over $84 \%$, what makes it one of the smaller, after the 4th cluster, which is the evidence of better saving possibilities for households of young, never married people.

Another (the 2nd) cluster has been formed by the people age 50 and over (92\%), with over $79 \%$ female households, and with post-employment benefits as the main income source for over $3 / 4$ households. The majority of people in this group of households had middle or higher education. The households were localized at various settlement units. The specific features in this group were the largest expenditures 
on health service and relatively high expenditures on food, non-alcoholic beverages, furnishing and other consumption goods and services. Relatively low expenses were designated for education, catering services and accommodation. In relation to other groups, high share of expenditures on dwelling maintenance $(25.0 \%)$, health service $(8.4 \%)$, telecommunication $(4.9 \%)$ and other goods and services $(7.1 \%)$; meanwhile smaller percentage of expenditures on catering services and accommodation (3.2\%) was observed. The share of expenditures on consumption goods and services in disposable income was about $92 \%$, what makes it the highest of all the clusters, which is evidence of the smallest saving tendency, although disposable income for these households were higher than in two further clusters.

The 3rd cluster contained, above all, people of the age between 50 and 70 (75\%). There were usually male households (about 2/3), with head having rather low education level. The main income sources for $92 \%$ of households were post-employment benefits, pensions and other social benefits. The 3rd cluster households were localized at rural areas $(46 \%)$ or in smaller towns - up to 99,000 dwellers (31\%). The specific features in this group were the lowest levels both of disposable income and expenditures on main categories of consumption goods and services; with the exception of education services and expenses connected with catering services and accommodation. The value of social benefits, i.e. the main income source for this cluster, is generally lower than value of salaries or self-employment income, so the expenditures on some consumption goods and services are relatively low, and, consequently - in consumption pattern only basic needs are covered. In the structure of disposable income, the largest percentage of expenditures on food and non-alcoholic beverages $(28.0 \%)$ was noticed. Relatively high percentage of expenditures was designated on catering services and accommodation (7.6\% of disposable income). The lowest percentage of disposable income, in comparison to other clusters, was for clothing and footwear $(2.3 \%)$, dwelling maintenance $(2.3 \%)$, transportation $(2.9 \%)$ as well as culture and leisure $(3.5 \%)$. Moreover, alcoholic beverages and tobacco products $(2.5 \%)$. The share of expenditures on consumption goods and services in disposable income was $87 \%$, so it was equal to the households in 5th cluster, although the 5 th cluster is characterized by significantly higher level of disposable income.

The further, 4th cluster was represented by households of people of the age 40-70, especially male (76\%), poorer educated (over a half had vocational training, less than $1 / 4$ completed lower secondary school or even not). The main source of income for $43 \%$ of households were blue-collar jobs and for $14 \%$ - agricultural labour. 54\% of 4th cluster households were located at rural area. The distinctive feature for this group was relatively high level of expenditures on alcoholic beverages and tobacco products and the lowest level of health service spending. Comparably, in the structure of disposable income, the share of expenditures on alcoholic beverages and tobacco products $(5.3 \%)$ was the highest of all the clusters, while the share of expenses on health service $(2.7 \%)$ and for other goods and services (3.4\%) were the lowest of all. The behaviours of these household members seem to be rather risky. The share of expenditures on consumption goods and services in disposable income was $80 \%$, what makes it the lowest of all clusters.

The last (the 5th) cluster was formed by of people of the age between 40 and 60 (73\%), working for a living in white-collar jobs $(60 \%)$ or self-employed (24\%). 59\% of these households were female. $84 \%$ of the people representing the 5 th cluster had higher education. In this group, the highest level of disposable income was noted. The level of expenditures on consumption goods and services - especially on food and non-alcoholic beverages, furnishing, transportation, culture and leisure and others was also the highest. As for disposable income, relatively low, as compared to other clusters, was the share of expenditures on food and non-alcoholic beverages (13.6\%) and dwelling maintenance $(15.5 \%)$. Meanwhile, high share of disposable income was observed in expenditures on furnishing $(6.1 \%)$, transportation $(14.4 \%)$, culture and leisure $(9.5 \%)$ and other consumption goods and services (7.4\%). High disposable income of these households make possible to meet high-order needs. The share of expenditures on consumption goods and services in disposable income was over $87 \%$, and it was one of the highest among all clusters. 
Groups of households with a dominant percentage of men had different consumption patterns from groups of households with women's domination. In men's households more were spent on alcoholic beverages and tobacco products as well as on gastronomy and accommodation compared to households run by women. These results are also confirmed by studies from other countries (Changpetch et al., 2016). It is argued that women are more aware of the health effects of consumption of stimulants.

The age and sex of people creating households were also associated with expenses for catering services. In households with older people are more time to cook home-made meals and are less familiar with the use of (the rather more recent) ready-made meals and products (Daniels and Glorieux ,2015), own research confirms the observed regularity. In the group of households created mainly by women over 50 years old, the smallest expenditures on catering services were recorded. Older-generation households have different cultural values and food perceptions than younger households as ready meals are less likely to appear on their table (Daniels and Glorieux, 2015). The lifestyle of older people is changing, among others by the dynamic development of medical services. The stereotypical image of lonely and poor elderly people is slowly replaced with the image of active people, with a hedonistic approach to life.

\section{CONCLUSIONS}

The proportion of one-person households in total number of households remains in similar level in Poland; however the proportion of one-person households of never married continues to grow, which makes this type of households the interesting research area. In the study it was shown that one-person households of never-married have various consumption patterns, influenced by economic and socio-demographic features as well as connected with household localization. In general, it can be concluded that distinguishing the consumption patterns for one-person households of never married is possible on the basis of diversification both level and structure of incomes in these households as well as socio-demographic differences between them. Depending on economic and socio-demographic variables, disparate consumption patterns for these types of households can be observed.

As for the further research, it seems to be worth establishing the diagnosis for consumption patterns in other types of one-person households, considering household head's marital status. These results could be compared with consumption patterns presented above.

\section{Acknowledgements}

The study was financed from the budget of the city of Płock in connection with the Competition of the President of the City of Płock for financing research grants carried out as part of the task 'Cooperation with universities'.

\section{REFERENCES}

1. Bachman, D., Barua, A. (2015). Single-person households: Another look at the changing American family. Deloitte. Insights.

2. Candel, M. (2001). Consumers' convenience orientation towards meal preparation. Conceptualization and measurement. Appetite, 36 (1), pp. 15-28

3. Changpetch, P., Haughton, D., Le, M., Ly, S., Nguyen, P., Thach, T. (2016). Alcohol consumption in Thailand: A study of the associations between alcohol, tobacco, gambling, and demographic factors. Retrieved from: https://hal.archives-ouvertes.fr/hal-01271254.

4. Dąbrowska, A., Janoś-Kresło, M. (2011). Single jako konsumenci usług rynkowych ze szczególnym uwzględnieniem usług turystycznych. [Singles as consumers of market services with particular emphasis on tourist services]. Zeszyty Naukowe Uniwersytetu Szczecińskiego. Problemy Zarządzania, Finansów i Marketingu, 22, pp. 377-388.

5. Daniels, S., Glorieux, I. (2015). Convenience, food and family lives. A socio-typological study of household food expenditures in 21st-century Belgium. Appetite, 94, pp. 54-61.

6. Harris, J.M., Shiptsova, R. (2007). Consumer demand for convenience foods. Demographics and expenditures. Journal of Food Distribution Research, 38 (3), pp. 22-36.

7. Jo, P.K. (2016). The Effects of the Economic Characteristics of Single-person Households on the Food Service Industry. Korean Journal of Community Nutrition, 21 (4), pp. 321-331. 
Proceedings of the 2018 International Scientific Conference 'Economic Sciences for Agribusiness and Rural Economy' No 2, Warsaw, 7-8 June 2018, pp. 75-80

8. Masnick, G. (2015) The Rise of the Single-Person Household. Harvard Joint Center for housing Studies. Retrieved from: http://housingperspectives.blogspot. com/2015/05/the-rise-of-single-person-household. html. [Accessed 01.03.2018].

9. Palmer, G. (2006). Single person households. Joseph Rowntree Foundation, New Policy Institute.
10. Piekut, M. (2017). Wzorce konsumpcji według typów wiejskich gospodarstw domowych w latach 2004-2014 [Consumption patterns according to types of rural households in 2004-2014] Difin, Warszawa.

11. Yeung, W.J.J., Cheung, A.K.L. (2015). Living alone: One-person households in Asia. Demographic Research, 32, pp. 1099-1112. 